\title{
Entrevista com Guilherme da Silva Braga
}

\author{
Marina Della Valle, John Milton, Telma Franco
}

Para algo tão antigo quanto a humanidade é paradoxal que o tema sexo continue a gerar embaraço em tanta gente. É fato que a situação mudou muito através dos tempos, tanto na vida das pessoas quanto nas publicações e traduções de obras eróticas e pornográficas. O que antes podia acarretar censura, recolhimento de material já impresso e até a prisão de autores, tradutores e editores, hoje é vendido em livrarias sem maiores constrangimentos na maioria dos países. Em outros, a questão é mais séria, e o castigo continua a apavorar editores e tradutores e a oprimir leitores, embora o tema inevitavelmente persista em publicações clandestinas.

Nos locais onde livros eróticos e pornográficos já não causam grandes celeumas, o trabalho do tradutor não sofre com ameaças externas, mas engloba peculiaridades próprias que, se não deixam de ser intrigantes, tampouco são desafios menores.

Foi por esse território acidentado, cheio de particularidades, que Guilherme da Silva Braga se enveredou quando foi convidado pela L\&PM para traduzir Incesto, de Anaïs Nin, um dos nomes mais conhecidos da literatura erótica. Antes, Braga havia traduzido, pelo prazer do trabalho, Venus and Tanhäuser, de Aubrey Beardsley, trabalho ainda inédito. Para a série Erótica, da Hedra, sugeriu a publicação de Teleny ou O Reverso da Medalha, obra atribuída a Oscar Wilde, e levou a cabo a tradução de Flossie, a Vênus de 15 Anos, também sem 
John Milton, Marina D. Valle, Telma Franco. Entrevista com Guilherme da Silva Braga

autoria confirmada, atribuída a Algernon Charles Swinburne. O livro, considerado o Garganta Profunda da era vitoriana, é um divertido relato sobre sexo consensual - e entusiasmado - entre a Vênus de 15 anos do título, Eva, sua amiga mais velha, e o sortudo capitão Jack Archer, que cai nas graças das duas. Outra obra de Nin, Fogo, volume de seus diários sem cortes, está no prelo.

Na entrevista a seguir, Braga, que nos brinda nesta edição com traduções de contos eróticos de Arthur Schnitzler e de Leopold Ritter von Sacher-Masoch - autor emblemático cujo nome batizou o masoquismo -, comenta a experiência com obras em que o sexo dá o tom, a ambiguidade na divisão entre o que é considerado erótico e o que é tido como pornográfico, percalços encontrados e soluções adotadas, entre outros detalhes em torno de um tema que jamais perde o fascínio.

Como você se aproximou da tradução de literatura erótica e pornográfica?

Antes mesmo de 2005, quando comecei a traduzir profissionalmente, eu já tinha lido alguns dos clássicos libertinos - ou seja, apesar de a experiência tradutória com esse gênero de literatura ter sido uma coisa nova, o contato com ela não foi. Era algo que eu já conhecia, tanto que eu já tinha feito, por puro diletantismo, a tradução de um romance pornográfico inédito em português escrito pelo Aubrey Beardsley (Venus and Tannhäuser), que ainda pretendo ver publicado.

No fim de 2006 recebi o convite da L\&PM para traduzir um livro que me foi apresentado em tom de brincadeira como sendo "de mulherzinha". Ao descobrir que se tratava do Incesto, da Anaïs Nin, eu já tinha uma idéia mais ou menos clara do que iria encontrar. Comecei a ler vários livros dela, o que foi muito conveniente, pois a tradução que me tocou a seguir foi mais um volume dos diários sem cortes da Anaïs, chamado Fogo (L\&PM, no prelo). 
Mais tarde, no início de 2008, a Hedra me pediu sugestões de títulos eróticos inéditos em português. Sugeri alguns e dentre eles Teleny, ou O Reverso da Medalha (trad. de Francisco Innocêncio) e Flossie, a Vênus de Quinze Anos (tradução minha) foram publicados na série Erótica da editora.

Desde então venho traduzindo outras coisas, mas a experiência com a literatura erótica foi proveitosa. Afinal, livros de todos os tipos tratam de sexo mais cedo ou mais tarde.

Quais as principais dificuldades encontradas na tradução de obras explicitamente pornográficas?

Creio que sejam duas: as inúmeras descrições do ato sexual em si, que, por mais que seja narrado mil vezes de mil formas diferentes, é sempre uma variação sobre um único tema eterno, e também - no caso de obras mais satíricas ou humorísticas, como Flossie - a manutenção do contraste entre o tom elevado da narração e a profusão de palavras absolutamente chulas.

Para você, o que delimita o campo da literatura erótica do campo da pornográfica? É possível fazer uma separação consistente?

De maneira um tanto rudimentar, me parece que a pornografia tem o sexo como fim estético, enquanto o erotismo o tem como meio. Mas os detalhes são muito mais complexos do que isso. $\mathrm{O}$ conteúdo sexual explícito e o nível de perversão que o leitor atribui a um texto, por exemplo, parecem ter pouco a ver com essa diferenciação, ao menos da maneira como ela é comumente feita. Flossie, a Vênus de Quinze Anos trata de três pessoas que passam o tempo inteiro fazendo sexo consensual e divertido. No entanto, é classificado como um livro pornográfico. A Anaïs Nin, por outro lado, escreveu muitos contos sexuais violentos e perturbadores, incluindo um (The Woman on the Dunes) sobre uma mulher que assiste a um enforca- 
mento em praça pública enquanto é penetrada por trás por um estranho, que ejacula dentro dela no instante em que o condenado cai para a morte. Mesmo assim, a obra dela é amplamente percebida como literatura erótica.

No plano das outras artes acontece o mesmo. Fotógrafos como Graham Ovenden, Jock Sturges e Fábio Cabral já protagonizaram diversos escândalos e tiveram obras suas em que meninas apareciam nuas ou seminuas em contextos não sexuais apreendidas e enfrentaram processos judiciais, acusados de pornografia infantil e obscenidade. Enquanto isso, nos prostíbulos de Shinjuku, Nobuyoshi Araki tirou fotografias reais de sexo explícito e fetichismo - algumas delas similares às imagens que se veem em qualquer revista pornográfica - e com elas fez um livro que figura na seção de arte de qualquer livraria que se preze. No cinema, "Brokeback Mountain" [lançado no Brasil como "O Segredo de Brokeback Mountain"] causou revolta e foi alvo de censura, em 2005, por conta das cenas supostamente indecentes e amorais que exibe. Só que em 1988, na Finlândia, Teemu Mäki fez um filme em que aparece matando um gato a machadadas e se masturbando em cima do cadáver - material este posteriormente comprado pelo museu Kiasma a título de arte. Otto Muehl também entrou para a história da arte com um filme em que um ganso vivo tem a cabeça cortada e o pescoço enfiado entre as pernas de uma atriz empapada com o sangue do animal.

Quanto mais nos aproximamos desses casos-limite, mais a distinção se torna difusa.

No que tange à tradução de Flossie, de 1886, como foi a pesquisa de termos considerados chulos? Alguma surpresa nessa tarefa? Os termos em português não destoam dos utilizados hoje em dia...

Muitos dos termos usados na tradução de Flossie são metafóricos no original em inglês; assim, sempre que o termo original descrevia algum objeto fálico para se referir ao pênis, por exemplo, op- 
tei por manter a metáfora em português. Foi o que ocorreu com yard e column, traduzidos por "verga", "vara" (entre outros) e "pilastra", respectivamente. Em relação aos termos mais explícitos, não houve surpresas - a maioria deles ainda é corrente em inglês, como prick, cunt e fuck. A coincidência entre muitos dos termos que usei e que são usados ainda hoje se justifica pela antiguidade do vocabulário chulo tanto na língua de partida como na língua de chegada: o Merriam-Webster registra as primeiras ocorrências de fuck e cunt já no século XIV. No português, as palavras "caralho" e "foder", segundo o Houaiss, encontram-se registradas a partir do século XIII.

Mesmo assim, em alguns casos isolados optei por usar palavras que soassem algo datadas ou estranhas para evitar que o leitor tivesse a impressão de estar lendo um texto contemporâneo: é o caso de "porraz" ("pênis"), palavra que nem sequer aparece nos dicionários, mas que foi usada por Bocage, e de "minete" e "broche", que foram usadas para referir-se à cunilíngua e à felação, dependendo do sentido em que o original empregava o verbo to gamahuche (obviamente decalcado do francês), que por sua vez denota a prática do sexo oral em pessoas de ambos os sexos. A palavra nut, no sentido de "glande", também foi traduzida por "chapeleta", um tabuísmo que, embora pouco conhecido, é de compreensão imediata no contexto em que aparece.

Talvez o caso mais interessante tenha sido a tradução da frase militar storm the breach, metáfora usada em duas ocasiões pelo capitão Jack Archer para se referir ao instante em que penetra Eva, uma de suas companheiras. A frase militar equivalente mais comum em português é "subir à brecha", mas, embora "brecha" seja uma metáfora absolutamente plausível para "vagina" em português, "subir" é um verbo de pouca conotação sexual, e o "à" transmite mais uma idéia de "até a", não de "para dentro de" (como ocorre no emprego militar legítimo da frase). Um pouco mais de pesquisa fez com que eu encontrasse, principalmente em livros do séc. XIX, um sinônimo bem menos frequente que caiu como uma luva: "montar a brecha". 
John Milton, Marina D. Valle, Telma Franco. Entrevista com Guilherme da Silva Braga

Na tradução de obras tão explícitas como Flossie e Incesto, de Anaïs Nin, como lidar com possíveis pudores e limitações internas, ainda que não conscientes, do tradutor? Você desenvolveu alguma maneira de driblar as possíveis reações inconscientes perante o texto?

Apesar do título, Incesto não é uma obra tão explícita como a fama do livro sugere. Há cenas de natureza sexual, mas elas ocupam poucas das quase quatrocentas páginas do livro. Além do mais, essas descrições são bastante humanas, com detalhes sobre os participantes, descrições de cheiros, gostos, sentimentos - não se trata de um simples zoom em órgãos genitais com uma ejaculação no final. E foi justamente isso o mais difícil da tradução: manter esse tom intimista, sexual, que no entanto nunca chega a ser chulo. $O$ fato de o livro ter sido escrito por uma mulher também foi desafiador, pois a perspectiva feminina em relação ao sexo é algo a que não estamos acostumados.

Já em Flossie tudo é tão caricato que beira o surrealismo - o sexo parece muito menos sério. Como acontece a muitas outras obras eróticas, o livro é marcado pelo humor. E traduzir humor é sempre um desafio, embora isso não seja uma dificuldade específica da literatura erótico-pornográfica.

Quanto a saber enfrentar os tabus relacionados ao sexo, julgo que seja absolutamente necessário. Entendo que pode haver tradutores que lá por suas razões pessoais preferissem não traduzir um livro pornográfico, assim como muitos outros não aceitariam traduzir um livro de poesia, mas cenas de sexo - assim como poemas - aparecem em todo tipo de texto quando menos se espera e nós temos que saber o que fazer. Um dos últimos livros que traduzi - A Arte da Ficção, do David Lodge - era de crítica literária. O livro tem uma citação do William Cooper em que uma personagem faz sexo oral no namorado. Não é explícito, mas está lá. Um tradutor mais recatado vai fazer o quê, devolver o livro nesse ponto? Não dá. 

eróticos?

Que aspectos você considera interessantes na tradução de textos

Não considero a tradução de textos eróticos nem mais nem menos interessante do que a tradução de outros textos literários. Tem lá suas especificidades - é um desafio e tanto no que tange resolver confusões pronominais que surgem na tradução portuguêsinglês, por exemplo -, mas afora isso é uma tradução como qualquer outra.

$\mathrm{Na}$ esfera puramente pessoal, me agrada traduzir esses livros porque são textos que como leitor eu aprecio. critérios?

Como avaliar a qualidade de um texto erótico? É possível estabelecer

Sem dúvida, mas não acho que os textos eróticos mereçam critérios especiais, uma vez que antes de qualquer outra coisa são textos literários.

Nos textos ditos eróticos, o sexo (sugerido ou explícito) aparece em um contexto mais amplo, e é à luz desse contexto que deve ser visto. Um leitor que pule trechos de Lolita ou de O Amante de Lady Chatterley para chegar o mais depressa possível aos trechos propriamente sexuais faria melhor se lesse revistinha de sacanagem. Sem dúvida o sexo é parte integral dessas obras, mas o valor delas não está em versar sobre um homem obcecado por uma ninfeta ou uma mulher que gosta de transar com o couteiro.

Você leu outras traduções de textos de Anaïs Nin e Swinburne antes de se lançar às próprias traduções das obras deles, e em que essa leitura lhe foi útil?

Enquanto traduzi Incesto eu estava morando em Budapeste, então eu não tive acesso a livros brasileiros. Mas li vários outros 
livros da Anaïs Nin em inglês - tanto os diários como a ficção -, e também alguns livros do Henry Miller, para conhecer melhor o estilo literário e a vida dela na época dos acontecimentos narrados em Incesto. Essa leitura paralela de outras obras do autor é algo que eu sempre faço e que sempre me ajuda muito na tradução.

No caso de Flossie, ao que tudo indica o livro não é do Swinburne. Na introdução que escrevi, menciono que esta atribuição, apesar de histórica, não parece ter o menor fundamento na realidade, então eu traduzi o texto como se fosse de um autor anônimo. A única coisa indubitavelmente escrita pelo Swinburne em todo o texto de Flossie é a epígrafe - duas estrofes do poema "Dolores" -, e neste caso me preocupei em ler a tradução feita pelo Carlos Vogt, embora a tradução constante na edição da Hedra seja minha.

Historicamente, sempre houve preconceito com obras eróticas. Você percebeu algum tipo de preconceito ou atitude diferenciada em relação a seu trabalho quando se enveredou pelo erotismo?

Uma vez contatei uma editora de livros infantis que estava procurando tradutores. Mandei um currículo e fiz um teste, que foi elogiado, mas me disseram que eu não tinha o perfil para traduzir as obras em questão. Não sei se teve algo a ver com os títulos "eróticos" no meu currículo, mas não é impossível.

Seja como for, esse preconceito em relação a livros eróticos me surpreende. A Bruna Surfistinha apareceu em tudo quanto foi revista, jornal e programa de tevê quando lançou o livro dela sobre a vida de garota de programa que levou por alguns anos. O livro da Tony Bentley sobre as experiências dela com o sexo anal foi resenhado em grandes periódicos. O lançamento de Flossie e Teleny foi citado na "Veja", no "Globo", na "Gazeta Mercantil" e provavelmente em outros lugares também. Será que se as pessoas não estivessem interessadas em literatura erótica e pornográfica esse tipo de livro renderia tanta notícia em periódicos de circulação tão ampla? Ou mesmo um segundo livro, como no caso da Bruna Surfistinha? 
Meu relacionamento com as editoras para as quais venho trabalhando segue tranquilo, até porque, no caso da Anaïs Nin, foi a própria L\&PM que me encomendou as traduções, e no caso de Flossie e Teleny foi a Hedra que teve por bem acatar as minhas sugestões.

Mesmo assim, não me considero um tradutor de livros eróticos. Este é apenas um dos gêneros literários pelos quais me interesso.

Na época de Shakespeare, a palavra sport também queria dizer "sexo". Você pode pensar em palavras da língua portuguesa que perderam seu duplo sentido?

Na verdade o que mais me intriga é justamente o contrário: a capacidade que as palavras têm de adquirir e sugerir conotações sexuais mesmo contra a nossa vontade. Acho curiosas, por exemplo, as histórias que já ouvi de pessoas que inadvertidamente acabaram falando alguma obscenidade em língua estrangeira por não conhecer um segundo significado sexual ou ofensivo de uma palavra corriqueira. Nunca ouvi histórias de gente que tenha feito um elogio acidental, um pedido de casamento ou de socorro acidental: se alguém tem uma história para contar sobre algum mal-entendido em língua estrangeira, quase sempre envolve um desaforo, um palavrão, uma obscenidade. 